\title{
Potencial produtivo de genótipos de feijão comum em função do estresse de fósforo no Estado do Tocantins
}

\section{Yield potential of common bean cultivars in function of phosphorus stress in State of Tocantins}

\author{
Taynar Coelho de Oliveira ${ }^{1}$, Joedna Silva ${ }^{1}$, Sérgio Alves de Sousa ${ }^{1}$, Raphael Campestrini ${ }^{1}$ e \\ Rodrigo Ribeiro Fidelis ${ }^{{ }^{*}}$
}

${ }^{1}$ Departamento de Agronomia; Universidade Federal do Tocantins; 77402-970; Gurupi - TO - Brasil.

\begin{abstract}
This work was developed in order to evaluate the yield potential of 11 common bean cultivars submitted to phosphorus stress. The research was carried in the experimental area of "Universidade Federal do Tocantins Campus Universitário de Gurupi". The experimental design was complete randomized blocks with four replications. To represent a stressing environment $20 \mathrm{~kg} \mathrm{ha}^{-1}$ of $\mathrm{P}_{2} \mathrm{O}_{5}$ was applied at seeding time. The evaluated characteristics were: plant height, height of first pod insertion, stem diameter, number of pods, number of gains per pod, one hundred gains mass, index of chlorophyll $a, b$, total and grain yield. It was concluded that the genotypes IPREldorado and IPR-Colibri presented the better yield potential under phosphorus stress condition. Even under phosphorus stress, most cultivars presented plant height and height of first pod adequate to mechanized cropping systems.
\end{abstract}

Key-words: Phaseolus vulgaris, cerrado, mineral stress

\section{INTRODUÇÃO}

O feijoeiro comum (Phaseolus vulgaris L.) é a espécie mais cultivada entre as demais do gênero Phaseolus. Considerando somente o gênero Phaseolus, o Brasil é o maior produtor, seguido do México (Yokoyama, 2003).

No Brasil, o feijão comum é uma leguminosa bastante cultivada e consumida, apresentando assim como um alimento de alta expressividade tanto no caráter econômico como social. As condições climáticas diversificadas no país possibilitam o cultivo durante todo o ano, sendo normalmente cultivada na maioria das vezes em pequenas propriedades.

Segundo a Companhia Nacional de Abastecimento (Conab, 2011) os estados da região norte e nordeste possuem baixa produtividade de grãos, devido principalmente, às condições climáticas e a utilização de cultivares não adaptados a região. No entanto, o estado do Tocantins vem demonstrando grande potencial para exploração desta cultura nos solos do cerrado, visto que, a produtividade de grãos estadual nos últimos anos superou a média nacional (Conab, 2011).

Entre os nutrientes, o fósforo (P) é aquele que frequentemente mais limita a produção das culturas nos solos da região de Cerrado (Carvalho et al., 1995), porém, os efeitos podem ser minimizados quando utilizam algumas práticas como a correção da acidez do solo, adubação fosfatada adequada e utilização de cultivares eficientes ao uso de fósforo.

Desta forma, a identificação de cultivares eficientes ao uso de fósforo pode ser uma estratégica para conseguir maiores produtividades de grãos em solos tropicais. Diversos autores relatam as diferenças entre os genótipos quanto à absorção e utilização do fósforo em culturas anuais, como Feijão (Franzini, 2010; Fageria, 1998; Singh et al.,1989; Yan et al., 1995), milho (Fidelis et al., 2009; Fidelis et al., 2010) e arroz (Rotili et al., 2010).

*Author for correspondence: fidelisrr@uft.edu.br 
Diante do exposto, objetivou-se com essa pesquisa avaliar o potencial produtivo de cultivares de feijão comum submetido a estresse de fósforo, na entressafra, no estado do Tocantins.

\section{MATERIAL E MÉTODOS}

O experimento foi conduzido na estação experimental da Universidade Federal do Tocantins, Campus Universitário de Gurupi, localizado a $11^{\circ} 43^{\prime} 45^{\prime \prime}$ de latitude sul e $49^{\circ} 04^{\prime}$ 07 “ longitude oeste, a $280 \mathrm{~m}$ de altitude. O solo é classificado como Latossolo Vermelho - Amarelo distrófico (Embrapa, 2006), textura média.

Antes da instalação do experimento foram coletadas amostras de solo na camada $0-20 \mathrm{~cm}$, cuja análise química e física revelou os seguintes resultados: $\mathrm{pH}$ em $\mathrm{CaCl}_{2}=4,56$; $\mathrm{M} . \mathrm{O}(\%)=1,8 ; \mathrm{P}$ $(\mathrm{Mel})=3,22 \mathrm{mg} \mathrm{dm}{ }^{3} ; \mathrm{K}=23,61 \quad \mathrm{Ca}+\mathrm{Mg}=3,15$ $\mathrm{cmol} \mathrm{dm}{ }^{3} ; \mathrm{H}+\mathrm{Al}=3,03 \mathrm{cmol} \mathrm{dm}^{3} ; \mathrm{Al}=0,0 \mathrm{cmol}$ $\mathrm{dm}^{3} ; \mathrm{SB}=3,21 \mathrm{cmol} \mathrm{dm}^{-3} ; \mathrm{V}=51,47 \% ; 732,94 \mathrm{~g}$ $\mathrm{kg}^{-1}$ de areia; $71,60 \mathrm{~g} \mathrm{~kg}^{-1}$ de silte e $195,46 \mathrm{~g} \mathrm{~kg}^{-1}$ de argila.

O preparo do solo foi realizado de forma convencional, com aração e gradagem. Para realização deste estudo, foram usadas sementes de 11 cultivares de feijão comum, sendo IPR-Colibri, IPR-Eldorado, Jalo Precoce, IAC-Una, BRSDiamante Negro, Safira, IPR-Chopim, BRSHorizonte, BRS-Requinte, IAC-Alvorada e BRSPontal.

$\mathrm{O}$ experimento foi conduzido em delineamento em bloco ao acaso com quatro repetições. A semeadura foi realizada em junho de 2011 e para a adubação de implantação utilizou-se $20 \mathrm{~kg} \mathrm{ha}^{-1}$ de $\mathrm{P}_{2} \mathrm{O}_{5}$ na forma de super simples e $60 \mathrm{~kg} \mathrm{ha}^{-1} \mathrm{de}$ $\mathrm{K}_{2} \mathrm{O}$. Na adubação de cobertura aplicou-se $90 \mathrm{~kg}$ $\mathrm{ha}^{-1}$ de $\mathrm{N}$ na forma de sulfato de amônia aplicada 20 dias após a emergência. Cada parcela experimental foi constituída por quatro linhas de $5,0 \mathrm{~m}$ de comprimento, espaçadas de $0,45 \mathrm{~m}$, visando obter um estande final de 12 plantas por metro linear. Como área útil foram consideradas as duas linhas centrais desprezando $0,50 \mathrm{~m}$ de cada extremidade.

Aplicou-se duas vezes o inseticida pertencente ao grupo químico Organofosforado (500 g i.a./ha), aos 27 e 37 dias após o plantio. O controle de plantas daninhas foi realizado até 58 dias após o plantio com aplicações de herbicidas pertencente aos grupos químicos: Oxima ciclohexanodiona $(400 \mathrm{ml} / \mathrm{ha})$, acido arilozifenoxipropiômico $(75 \mathrm{~g}$ i.a./ha) e benzotiadiazinona (1200 $\mathrm{ml} / \mathrm{ha})$.
Para identificação do potencial produtivo dos cultivares de feijão foram avaliadas cinco plantas aleatórias e representativas na área útil da parcela. As características avaliadas foram: Altura da planta: medindo do colo da planta até o final da haste principal; Altura de inserção de primeira vagem: medindo do solo até o ponto de inserção da primeira vagem; Diâmetro do caule: medindose o caule da planta com paquímetro digital. Número de vagens por planta: sendo obtido pela média de contagem do número total de vagens por planta; Número de grãos por vagem: obtido através da média do número total de grãos oriundos da planta e dividindo o resultado pelo número total de vagens; Número de grãos por planta: obtido através da média do número total de grãos oriundos da planta; Índice de clorofila $a, b \mathrm{e}$ total: foram realizadas três leituras por planta em cinco plantas por parcela, totalizando 15 leituras com um clorofilômetro marca ClorofiLOG ${ }^{\circledR}$ modelo CFL 1030 (Falker, 2008), do qual fornece medições dos índices das clorofilas a, b e total, sendo que as leituras foram realizadas no florescimento pleno, sempre na primeira folha completamente expandida; Massa de 100 grãos: tomando-se cem grãos da área útil pesando e corrigindo a umidade para 13\% anotando em gramas; Produtividade de grãos: feito através da massa de grãos da área útil em quilogramas, com correção para $13 \%$ de umidade transformando os dados para $\mathrm{kg} \mathrm{ha}^{-1}$.

As comparações entre as médias de todos os parâmetros analisados foram efetuadas por meio do teste de (Scott e knott, 1974) ao nível de 5\% de probabilidade. As análises foram realizadas com a utilização do aplicativo computacional Sisvar (Ferreira, 2008).

\section{RESULTADOS E DISCUSSÃO}

Observa-se na Tabela 1, que a fonte de variação genótipos apresentou significância para todas as características avaliadas, evidenciando que existe variabilidade genética entre os genótipos analisados. Verifica-se ainda valores baixos de coeficiente de variação para a maioria das características, excetuando para o número de vagem por planta e produtividade de grãos com 24 e $28 \%$, respectivamente. O que de acordo com Blum (1988), estes valores não são considerados inadequados, pois trata-se de ambiente sob estresse. Resultados semelhantes foram obtidos sob estresse mineral por Salgado (2011), que 
encontrou coeficiente de variação de 24 e $30 \%$ para as mesmas variáveis.

Tabela 1. Resumo da análise de variância das características altura de planta (AP), altura de inserção da primeira vagem (AIPV), diâmetro do caule (DC), número de vagem por planta (NVP), número de grãos por vagem (NSV), massa de 100 grãos (MCG), produtividade de grãos (PROD), clorofila $a$ (CLA), clorofila $b$ (CLB) e clorofila total (CLTOTAL) de onze cultivares de feijão comum, submetidos ao estresse de fósforo. Gurupi- Tocantins, 2011.

\begin{tabular}{cccccccccccc}
\hline \multirow{2}{*}{$\begin{array}{c}\text { Fonte de } \\
\text { Variação }\end{array}$} & GL & AP & AIPV & DC & NVP & NGV & MCG & PROD & CLA & CLA & CLTOTAL \\
\hline Genótipos & 10 & $617,88^{* *}$ & $30,49^{*}$ & $1,63^{* *}$ & $39,74^{* *}$ & $1,66^{* *}$ & $51,98^{* *}$ & $247706,87^{* *}$ & $1379^{* *}$ & $15,35^{* *}$ & $35,31^{* *}$ \\
Bloco & 3 & 166,87 & 24,84 & 0,35 & 2,58 & 0,25 & 1,00 & 42316,10 & 3,40 & 0,03 & 9,79 \\
Resíduo & 30 & 53,48 & 12,78 & 0,47 & 5,42 & 0,30 & 3,69 & 35625,12 & 2,90 & 3,05 & 7,38 \\
\hline Média & 55,5 & 18,54 & 5,34 & 9,37 & 3,43 & 22,21 & 674,06 & 36,67 & 14,62 & 50,89 \\
CV(\%) & 13,18 & 19,28 & 12,89 & 24,89 & 16,11 & 8,66 & 28,0 & 4,64 & 11,94 & 5,34
\end{tabular}

${ }^{\mathrm{ns}}$ não significativo; ${ }^{* *}$ significativo para $\mathrm{P}<0,01$; ${ }^{*}$ Significativo para $\mathrm{P}<0,05$ pelo teste $\mathrm{F}$.

Com relação à altura de planta (Tabela 2), verificase a formação de quatro grupos estatísticos, sendo que dois cultivares compuseram o grupo estatístico de maior média, sendo eles, o BRS-Pontal e IACAlvorada com 74,7 e 73,9 cm, respectivamente.

Tabela 2. Médias das características de altura de planta (AP), altura de inserção de primeira vagem (AIPV), diâmetro de caule (DC), número de vagens por planta (NVP), número de grãos por vagem (NGV) de onze genótipos de feijão comum submetidos ao estresse de fósforo. Gurupi- Tocantins, na entressafra de 2011.

\begin{tabular}{lccccc}
\hline Genótipos & $\begin{array}{c}\text { AP } \\
(\mathbf{c m})\end{array}$ & $\begin{array}{c}\text { AIPV } \\
(\mathbf{c m})\end{array}$ & $\begin{array}{c}\text { DC } \\
(\mathbf{m m})\end{array}$ & $\begin{array}{c}\text { NVP } \\
(\mathbf{u n d})\end{array}$ & $\begin{array}{c}\text { NGV } \\
(\mathbf{u n d})\end{array}$ \\
\hline IAC-Chopim & $56,1 \mathrm{c}$ & $20,2 \mathrm{a}$ & $5,6 \mathrm{a}$ & $8,9 \mathrm{c}$ & $4,0 \mathrm{a}$ \\
IPR-Eldorado & $40,4 \mathrm{~d}$ & $14,4 \mathrm{~b}$ & $4,9 \mathrm{~b}$ & $11,2 \mathrm{~b}$ & $4,7 \mathrm{a}$ \\
IPR-Colibri & $38,2 \mathrm{~d}$ & $16,3 \mathrm{~b}$ & $4,9 \mathrm{~b}$ & $16,2 \mathrm{a}$ & $3,2 \mathrm{~b}$ \\
BRS-Requinte & $66,0 \mathrm{~b}$ & $17,0 \mathrm{~b}$ & $4,6 \mathrm{~b}$ & $5,4 \mathrm{~d}$ & $2,7 \mathrm{~b}$ \\
BRS-Pontal & $74,7 \mathrm{a}$ & $20,0 \mathrm{a}$ & $5,2 \mathrm{~b}$ & $6,6 \mathrm{~d}$ & $3,2 \mathrm{~b}$ \\
BRS-Horizonte & $61,3 \mathrm{~b}$ & $21,0 \mathrm{a}$ & $5,9 \mathrm{a}$ & $9,6 \mathrm{c}$ & $4,0 \mathrm{a}$ \\
BRS-Diamante Negro & $51,6 \mathrm{c}$ & $19,0 \mathrm{a}$ & $4,9 \mathrm{~b}$ & $7,3 \mathrm{~d}$ & $3,9 \mathrm{a}$ \\
Safira & $55,5 \mathrm{c}$ & $20,4 \mathrm{a}$ & $4,8 \mathrm{~b}$ & $6,3 \mathrm{~d}$ & $3,1 \mathrm{~b}$ \\
IAC-Una & $46,9 \mathrm{~d}$ & $20,9 \mathrm{a}$ & $4,9 \mathrm{~b}$ & $9,0 \mathrm{c}$ & $3,1 \mathrm{~b}$ \\
IAC-Alvorada & $73,9 \mathrm{a}$ & $21,0 \mathrm{a}$ & $6,7 \mathrm{a}$ & $12,8 \mathrm{~b}$ & $2,7 \mathrm{~b}$ \\
Jalo Precoce & $45,9 \mathrm{~d}$ & $13,4 \mathrm{~b}$ & $5,8 \mathrm{a}$ & $9,6 \mathrm{c}$ & $2,8 \mathrm{~b}$ \\
\hline
\end{tabular}

Médias seguidas de mesma letra minúscula na coluna não diferem entre si pelo teste Scott - Knott a 5\% de probabilidade.

Para a característica altura de inserção de primeira vagem (Tabela 2), formaram-se apenas dois grupos estatísticos. Os cultivares que se sobressaíram estatisticamente apresentaram valores oscilando entre 21 e $19 \mathrm{~cm}$, enquanto que, o cultivar Jalo Precoce obteve menor inserção de primeira vagem, não diferindo dos cultivares com médias abaixo de $17 \mathrm{~cm}$. Neste sentido, a inserção de primeira vagem, de forma similar a altura de planta indica que para a maioria do cultivares os resultados dessas variáveis foram satisfatórias a colheita mecanizada, além que propiciar menores perdas de grãos. Deste modo, os resultados da pesquisa enquadram-se na recomendação de 
alguns autores (Yokomizo, 1999; Carvalho et al., 2010) onde relatam que a AIPV não pode ser inferior a $10 \mathrm{~cm}$, para facilitar a colheita $\mathrm{e}$ minimizar as perdas de grãos.

Quanto ao diâmetro de caule (Tabela 2), observase que os cultivares IAC-Alvorada, BRSHorizonte, Jalo Precoce e IAC-Chopim apresentaram os maiores diâmetros com valores variando entre 6,7 e $5,6 \mathrm{~mm}$. Neste sentido, os valores obtidos neste estudo demonstram-se adequados para uma boa sustentação da planta no solo, mesmo cultivado em condições estressantes de nutriente.

Para o número de vagem por planta (Tabela 2), houve uma formação de quatro grupos estatísticos. O primeiro grupo é constituído apenas por um cultivar o IPR-Colibri que se destacou dentre as demais com 16,2 vagens. Alguns estudos realizados por Petrilli (2007); Zucarelli et al. (2006) também foram encontrados resultados semelhantes aos desta pesquisa em condições de estresse mineral. Segundo autores como Fageria et al. (2004) e Ramalho et al. (1993), o componente que mais influência a produtividade é o número de vagens por planta.

Para a característica número de grãos por vagem, observa-se que o cultivar IPR-Eldorado apresentou melhor desempenho, apesar de não diferir, dos cultivares com médias acima de 3,9 grãos por vagem. O cultivar Jalo Precoce obteve o menor valor de número de grãos por vagem com médias de 2,7 .

Quanto ao índice de clorofila $a, b$ e total (Tabela 3 ), podê-se observar a formação de dois grupos para índice de clorofila $a$, o primeiro grupo apresentou resultados variando entre 39,4 e 37,66 ICF. Para a clorofila $b$, os valores oscilaram entre 18,6 e 11,2. Para clorofila total, os resultados variaram entre 56,1 e 44,8 ICF. Nota-se ainda que o cultivar BRS-Requinte compôs sempre o grupo estatístico de maior média de clorofila, o que evidencia sua maior capacidade para captação de luz.

Tabela 3. Médias de índice de clorofila $a$, $b$ e total, massa de cem grãos (MCG) e produtividade de grãos (PROD) de onze genótipos de feijão comum submetidos ao estresse de fósforo. GurupiTocantins, na entressafra de 2011.

\begin{tabular}{lccccc}
\hline Genótipos & $\begin{array}{c}\text { Clorofila } \boldsymbol{a} \\
(\mathbf{I C F})\end{array}$ & $\begin{array}{c}\text { Clorofila } \boldsymbol{b} \\
(\mathbf{I C F})\end{array}$ & $\begin{array}{c}\text { Clorofila total } \\
(\mathbf{I C F})\end{array}$ & $\begin{array}{c}\text { MCG } \\
(\mathbf{g})\end{array}$ & $\begin{array}{c}\text { PROD } \\
\left(\mathbf{K g ~ h a}^{-1}\right)\end{array}$ \\
\hline IAC-Chopim & $35,72 \mathrm{~b}$ & $14,37 \mathrm{~b}$ & $50,10 \mathrm{~b}$ & $20,58 \mathrm{~b}$ & $698 \mathrm{c}$ \\
IPR-Eldorado & $38,96 \mathrm{a}$ & $15,17 \mathrm{~b}$ & $54,14 \mathrm{a}$ & $22,08 \mathrm{~b}$ & $1.192 \mathrm{a}$ \\
IPR-Colibri & $37,66 \mathrm{a}$ & $14,75 \mathrm{~b}$ & $52,42 \mathrm{a}$ & $22,06 \mathrm{~b}$ & $1.043 \mathrm{a}$ \\
BRS-Requinte & $39,43 \mathrm{a}$ & $17,10 \mathrm{a}$ & $56,14 \mathrm{a}$ & $19,26 \mathrm{c}$ & $417 \mathrm{c}$ \\
BRS-Pontal & $35,36 \mathrm{~b}$ & $18,63 \mathrm{a}$ & $49,62 \mathrm{~b}$ & $24,27 \mathrm{~b}$ & $576 \mathrm{c}$ \\
BRS-Horizonte & $35,63 \mathrm{~b}$ & $13,84 \mathrm{~b}$ & $49,47 \mathrm{~b}$ & $22,08 \mathrm{~b}$ & $824 \mathrm{~b}$ \\
BRS-Diamante Negro & $35,26 \mathrm{~b}$ & $14,41 \mathrm{~b}$ & $49,68 \mathrm{~b}$ & $19,06 \mathrm{c}$ & $548 \mathrm{c}$ \\
Safira & $36,85 \mathrm{~b}$ & $14,77 \mathrm{~b}$ & $51,62 \mathrm{a}$ & $17,15 \mathrm{c}$ & $440 \mathrm{c}$ \\
IAC-Una & $35,91 \mathrm{~b}$ & $13,52 \mathrm{~b}$ & $49,44 \mathrm{~b}$ & $21,39 \mathrm{~b}$ & $566 \mathrm{c}$ \\
IAC-Alvorada & $38,44 \mathrm{a}$ & $13,04 \mathrm{~b}$ & $51,98 \mathrm{a}$ & $26,41 \mathrm{~b}$ & $504 \mathrm{c}$ \\
Jalo Precoce & $33,63 \mathrm{~b}$ & $11,24 \mathrm{~b}$ & $44,88 \mathrm{c}$ & $30,00 \mathrm{a}$ & $603 \mathrm{c}$ \\
\hline
\end{tabular}

Médias seguidas de mesma letra minúscula na coluna não diferem entre si pelo teste Scott - Knott a $5 \%$ de probabilidade.

Com relação à característica de massa de cem grãos, nota-se a formação de três grupos estatísticos (Tabela 3). O cultivar Jalo precoce apresentou superioridade estatística com média de 30 gramas por 100 grãos e o cultivar Safira teve menor massa de cem grãos com 17,15g apesar de não diferir dos cultivares com valores abaixo de $19,26 \mathrm{~g}$. Isto deu-se provavelmente, pela característica dos materiais genéticos, que apresenta sementes maiores (Jalo Precoce) e menores (Safira), por isso são classificados como tipo comercial de grãos manteiga e roxinho, respectivamente. Singh et al. (1989) relataram redução na massa de 100 grãos em feijão cultivado em solo com baixo teor de P. De acordo com Costa e Vieira (2000), os consumidores em geral possuem preferência quanto ao tipo de grãos, sendo o mais consumido o feijão carioca, devendo apresentar massa de cem grãos de aproximadamente $24 \mathrm{~g}$. 
Quanto à produtividade média de grãos (Tabela 3), observa-se a formação de três grupos estatísticos, sendo que, somente dois cultivares superaram a média nacional de $945 \mathrm{~kg} \mathrm{ha}^{-1}$ (Conab, 2011) e abaixo da média Estadual na safra 2010/2011 $\left(2139 \mathrm{~kg} \mathrm{ha}^{-1}\right)$. Desta forma, o primeiro grupo estatístico foi composto pelos genótipos IACEldorado e IPR-Colibri apresentando rendimento de grãos de 1192 e $1043 \mathrm{~kg} \mathrm{ha}^{-1}$, respectivamente. $\mathrm{O}$ segundo grupo foi constituído pelo cultivar BRS-Horizonte que obteve produtividade de grãos de $824 \mathrm{~kg} \mathrm{ha}^{-1}$. Dos 11 genótipos avaliados oito formaram $\mathrm{o}$ terceiro grupo, com resultados variando de 698 a $417 \mathrm{~kg} \mathrm{ha}^{-1}$. Zucareli (2005) estudando o comportamento do cultivar IACCarioca Tybatã em três níveis de fósforo encontrou produtividade de $1195 \mathrm{~kg} \mathrm{ha}^{-1}$ em solo deficiente. Silva et al. (2001) avaliando níveis de 0 a $140 \mathrm{~kg} \mathrm{ha}^{-1}$ de $\mathrm{P}_{2} \mathrm{O}_{5}$ tiveram a menor produtividade de $980,4 \mathrm{~kg} \mathrm{ha}^{-1}$.

Nota-se uma relação direta do número de vagem por planta e número de grãos por vagem com a produtividade de grãos, facilmente visualizado por meio dos cultivares IAC-Eldorado e IPR-Colibri que apresentaram os maiores números de vagem por planta obtendo assim destaque com relação ao rendimento de grãos. Enquanto que, o cultivar BRS-Requinte apresentou o pior desempenho para número de vagem por planta e sementes por vagem e, consequentemente, apresentou a menor produtividade de grãos. Fageria (1989) relata que a combinação de alguns fatores é determinante para atingir a produção máxima, sendo eles, o número de vagens por planta, o número de grãos por vagem e a massa dos grãos.

Em contrapartida, não foi observado à mesma relação direta entre índices de clorofila e produtividade de grãos, podendo ser visualizados por meio do cultivar BRS-Requinte que apresentou melhor índice de clorofila, porém, a menor produtividade de grãos.

\section{CONCLUSÕES}

Os genótipos IPR-Eldorado e IPR-Colibri apresentaram melhor potencial produtivo, sob condição estressante de fósforo;

A maioria dos cultivares mesmo sob estresse apresentaram altura de planta e altura de inserção de primeira vagem adequada ao cultivo mecanizado.
Objetivou-se com este trabalho avaliar o potencial produtivo de 11 cultivares de feijão comum submetidos a estresse de fósforo. A pesquisa foi desenvolvida no campo experimental da Universidade Federal do Tocantins - Campus Universitário de Gurupi. O delineamento experimental adotado foi de bloco ao acaso com quatro repetições. Para representar um ambiente de estresse aplicou-se $20 \mathrm{~kg} \mathrm{ha}^{-1}$ de $\mathrm{P}_{2} \mathrm{O}_{5}$ na semeadura. As características avaliadas foram: Altura de planta, altura de inserção de primeira vagem, diâmetro de caule, número de vagens, número de grãos por vagem, massa de cem grãos, índice de clorofila $a, b$ $e$ total e produtividade de grãos. Conclui-se que os genótipos IPR-Eldorado e IPR-Colibri apresentaram melhor potencial produtivo, sob condição estressante de fósforo. A maioria dos cultivares apresentaram altura de planta e altura de inserção de primeira vagem adequada ao cultivo mecanizado mesmo sob estresse mineral.

Palavras-chave: Phaseolus vulgaris, cerrado, estresse mineral

\section{REFERÊNCIAS}

Blum, A. Plant breeding for stress environments. CRC Press, Boca Raton. 223p., 1988.

Carvalho, A. M.; Fageria, N. K.; Oliveira, I. P.; Kinjo, T. (1995), Resposta do feijoeiro à aplicação de fósforo em solos dos cerrados. Revista Brasileira Ciência do. Solo, 19, 61-67.

Carvalho, E. R.; Resende, P. M.; Ogoshi, F. G. A.; Botrel, E. P.; Alcantra, H. P.; Santos, J. P.(2010), Desempenho de cultivares de soja [Glycine max (L.) Merril] em cultivo de verão no sul de Minas Gerais. Ciência e Agrotecnologia, 34, 892-899.

CONAB - Companhia Nacional de Abastecimento (2011) Feijão. Series históricas: área, produtividade e produção do boletim da Safra 2010/2011. Disponível em: $<$ http://www.conab.gov.br> Acesso em: $21 \mathrm{de}$ setembro de 2011.

Costa, J. G. C.; Vieira, N. R. A. Qualidade, classificação comercial e manejo pós colheita. In: Yokoyama, L. P. e Stone, L. F. Cultura do feijoeiro no Brasil: características da produção. Santo Antônio de Goiás: Embrapa Arroz e Feijão, 51-64, 2000.

Fageria, N. K. (1989), Effects of phosphorus on growth, yield and nutrient accumulation in the common bean. Tropical Agriculture, 66, 249-55.

\section{RESUMO}


EMBRAPA - Centro Nacional de Pesquisa de Solos, Sistema brasileiro de classificação de solos. $2^{a}$ ed. Brasília, EMBRAPA/DPI. 306p. 2006.

FALKER AUTOMAÇÃO AGRÍCOLA Ltda. Manual do medidor eletrônico de teor clorofila (ClorofiLOG / CFL 1030). Porto Alegre, Falker Automação Agrícola. 33p., 2008.

Fageria, N. K. (1998), Eficiência de uso de Fósforo pelos genótipos de Feijão. Revista Brasileira de Engenharia Agrícola e Ambiental, 2, 128-131.

Fageria, N. K.; Barbosa Filho, M. P.; Stone, L. F. Nutrição de fósforo na produção do feijoeiro. In: Simpósio de fósforo na agricultura Brasileira, 2003, São Pedro, Anais. Piracicaba: POTAFÒS, cap.17, p.435-455, 2004.

Fidelis, R. R.; Miranda, G. V.; Erasmo, E. A. L. (2009), Seleção de populações base de milho sob alta e baixa dose de fósforo em solo de Cerrado. Pesquisa Agropecuária Tropical, 39, 285-293.

Fidelis, R. R.; Miranda, G. V.; Pelúzio, J. M.; Galvão, J. C. C. (2010), Classificação de populações de milho quanto à eficiência e reposta ao uso de fósforo. Acta Scientiarum. Agronomy, 32, 241-246.

Ferreira, D. F. (2008), SISVAR: um programa para análises e ensino de estatística. Revista Symposium, 6, 36-41.

Franzini, V. I. Eficiência de uso de fósforo por cultivares de arroz e de feijoeiro e da fixação biológica de nitrogênio por cultivares de feijoeiro. Tese (Doutorado em solos e nutrição de plantas). Universidade de São Paulo- Escola Superior de Agricultura "Luiz de Queiroz", 2010.

Petrilli, L. R. T. C. Doses e modos de aplicação de fósforo na nutrição e produção do feijoeiro cultivar pérola. Dissertação (Mestrado em agronomia). Faculdade de Ciências Agronômicas, Universidade Estadual Paulista, Botucatu, 2007.

Ramalho, M. A. P.; Santos, J. B.; Zimmermann, M. J. O. Genética quantitativa em plantas autógamas: aplicações ao melhoramento do feijoeiro. Goiânia, Universidade Federal de Goiás, 271p., 1993.
Rotili, E. A.; Fidelis, R. R.; Santos, M. M.; Barros, H. B.; Pinto, L. C. (2010), Eficiência do uso e reposta à aplicação de fósforo de cultivares de arroz em solos de Terras Altas. Bragantia, 69, 705-710.

Salgado, F. H. M. Efeito do nitrogênio na produtividade de grãos e qualidade fisiológica de sementes de genótipos de feijão comum. Dissertação (Mestrado em Produção Vegetal) Universidade Federal do Tocantins, 2011.

Scott, A. J. and Knott, M. A. (1974), Cluster analysis method for grouping means in the analysis of variance. Biometrics, Washington, 30, 507-512.

Silva, E. B.; Resende, J. C. F.; Cintra, W. B. R. (2001), Resposta do Feijoeiro a doses de fósforo em solo arenoso. Ciência Rural, 31, 973-977.

Singh, S. P.; Urrea, C. A.; Gutierrez, J. A.; Garcia, J. (1989), Selection for yield at two fertilizer levels in small-seeded common bean. Canadian Journal of Plant Science, 65, 1011-1017.

Zucareli, C.; Junior, E. U. R.; Barreiro, A. P.; Nakagawa, J.; Cavariani, C. (2006), Adubação fosfatada, componentes de produção, produtividade e qualidade fisiológica em sementes de feijão. Revista Brasileira de Sementes, 28, 9-15. Zucareli, C. Adubação fosfatada, produção e desempenho em campo de sementes de feijoeiro CV. Carioca Precoce e IAC Carioca Tybatã. Dissertação (Doutorado em Agronomia). Faculdade de Ciências Agronômicas, Universidade Estadual Paulista, Botucatu, 2005.

Yan, X.; Lynach, J. P.; Beebe, S. E. (1995), Genetic variation for phosphorus efficiency of common bean in constrasting soil types. I. Vegetative response. Crop Science, 35, 10861093.

Yokomizo, G. K. Interação genótipos x ambientes em topocruzamentos de soja tipo alimento com tipo grão. Tese (Doutorado em Produção Vegetal) - Escola Superior de Agricultura Luis de Queiroz, Piracicaba, 1999. 
Yokoyama, L. P. A. importância econômica da cultura do feijoeiro. Santo Antonio de Goiás, 2003. (Documentos/Embrapa Arroz e Feijão, ISSN 1679-8869). 